\title{
Penerapan Metode Forward Chaining dengan Case-Based Reasoning pada Kerusakan Komputer
}

\author{
Asrul Sani ${ }^{1}$, Johan Ferdiyansyah ${ }^{2}$, Sumarsono $^{3}$, Bernadus Gunawan Sudarsono ${ }^{4}$, Dwi Yuniarto ${ }^{5}$
}

\begin{abstract}
Abstrak-Masa pertumbuhan teknologi saat ini komputer menjadi kebutuhan primer untuk sebagian besar manusia. Hampir segala bidang pekerjaan sangat bergantung dengan konsumsi teknologi dalam melaksanakan sesuatu pekerjaan. Salah satu teknologi yang banyak digunakan oleh banyak perusahaan merupakan komputer. Hal tersebut tidak terlepas dari permasalahan yang ada pada komputer tersebut. Salah satunya merupakan kerusakan komponen komputer disebabkan karena faktor kelalaian pengguna hingga bencana yang tidak terduga. Oleh karena hal tersebut pengguna rata-rata menggunakan jasa teknisi profesional untuk melakukan perbaikan suatu komputer, tetapi beberapa kelemahan dengan memanggil teknisi ahli yaitu mahalnya biaya yang akan dikeluarkan. Maka dari itu penulis di sini ingin membuat sebuah sistem yang dapat membantu para pengguna komputer untuk dapat mengidentifikasi serta memperbaiki perangkatnya secara mandiri. Pada penelitian ini menggunakan dua buah metode sebagai perbandingan, yaitu: metode forward chaining dan case-based reasoning. Hasil yang dapat diberikan dari metode forward chaining adalah berupa basis pengetahuan serta kesimpulan, sementara untuk metode case-based reasoning menghasilkan keluaran berupa nilai valid dari beberapa proses yang sudah dilakukan. Dari kedua metode tersebut dapat dikatakan bahwa metode case-based reasoning memliki akurasi yang tinggi di dalam menghasilkan suatu kesimpulan dikarenakan adanya perhitungan dan nilai yang didapat. Sistem ini dapat membantu bagi pengguna perangkat komputer untuk lebih mandiri di dalam merawat serta memperbaiki perangkat yang mereka miliki.
\end{abstract}

Kata kunci-Case Based Reasoning, Forward Chaining, Komputer.

\section{Pendahuluan}

$\mathrm{M}$

pertumbuhan teknologi saat ini komputer menjadi kebutuhan primer untuk sebagian besar manusia. Hampir segala bidang pekerjaan sangat bergantung dengan konsumsi

Received: 17 Januari; Revised: 5 Maret 2019; Accepted: 1 April 2019

A. Sani, Teknik Informatika, STMIK Widuri Jakarta, Indonesia (e-mail: asrulsani@kampuswiduri.ac.id)

J. Ferdiyansyah, Teknik Informatika, STMIK Widuri Jakarta, Indonesia (e-mail: johanferdian49@gmail.com)

Sumarsono, Prodi Teknik Informatika, UIN Sunan Kalijaga Yogyakarta, Indonesia (e-mail: sumarsono@uin-suka.ac.id)

B. G. Sudarsono, Prodi Sistem Informasi, Universitas Bung Karno Jakarta, Indonesia (e-mail: gunawanbernadus@ubk.ac.id)

D. Yuniarto, Prodi Teknik Informatika, STMIK Sumedang, Indonesia (e-mail: Duart0@stmik-sumedang.ac.id) teknologi di dalam melaksanakan sesuatu pekerjaan. Salah satu teknologi yang banyak digunakan oleh banyak perusahaan merupakan komputer, komputer banyak digunakan sebab memiliki sifat jangka panjang. Maksud dari jangka panjang tersebut ialah bisa digunakan dalam waktu yang lama serta bila terjadi suatu kerusakan, hanya harus mengubahnya dengan komponen lain yang lebih baru daripada wajib membeli baru seluruh komponen lain secara satu bundle. Sebagai contoh jika ditemukan masalah pada processor maka kita tidak butuh membeli komputer baru namun hanya membeli processor yang baru saja [1]. Manfaat dan fungsi dari komputer ini adalah dapat meringankan pekerjaan yang sulit dengan cara menggunakan atau membuat suatu software yang dapat membantu menuntaskan tugas tertentu secara otomatis. Kekurangan dari komputer ini sendiri antara lain pembelian komponen yang mahal, sulitnya dalam hal perakitan komponen, dan perawatan berkala yang wajib berhati hati seperti pembersihan debu pada processor, pembersihan motherboard dan yang lainnya [2].

Berdasarkan perkembangan komputer yang kita ketahui sampai sekarang, komputer pertama kali berbentuk perangkat yang bernama Abacus atau dapat disebut juga sempoa. Abacus ini hanya berfungsi sebagai alat hitung yang dimana cara kerjanya menggeserkan beberapa biji-bijian untuk menemukan perhitungan yang teratur. Penerapan alat yang bernama Abacus ini digunakan pada masyarakat untuk pembelian barang-barang kebutuhan. Memasuki generasi kedua dari perkembangan komputer akan menemukan suatu alat baru yang bernama resistor, transistor mulai digunakan awal pada tahun 1956 dan berfungsi sebagai pengganti tabung vakum yang ada di dalam televisi, radio dan komputer pada zaman itu [3].

Transistor sangat unggul jika dibandingkan dengan tabung vakum, akan tetapi seiring berjalannya waktu ditemukanlah masalah pada transistor yaitu pada saat pengunaannya menghasilkan panas yang berlebih dan itulah yang menjadi penyebab terciptanya sebuah alat baru. Alat baru yang dikembangkan oleh Jack Kilby pada masa komputer generasi ketiga tersebut diberi nama integrated circuit (IC). IC ini terbentuk dari beberapa komponen yang dimasukkan kedalam sebuah chip tunggal yang disebut juga semikonduktor. Setelah ditemukannya IC, tahap pengembangan komputer menjadi lebih jelas dengan cara memperkecil ukuran komponen dan sirkuit yang ada di dalamnya. Hal tersebut dapat dilihat dengan adanya media atau wadah yang bernama Large Scale Intergration (LSI). LSI ini sendiri dapat memuat komponen

http://journal.uinjkt.ac.id/index.php/aism 
kedalam sebuah chip hingga ratusan komponen. Tetapi hal itu dirasa kurang, oleh karena itu dibuatlah wadah yang dapat menampung komponen lebih banyak dari LSI bernama Ultra-LargeScale Integration (ULSI) .

ULSI ini dapat menampung hingga ribuan komponen dalam satu chip tunggal. Karena banyaknya perkembangan dan kemajuan di bidang desain komputer dan teknologi, hal itu juga yang menjadi acuan untuk kemungkinan dibuatnya komputer generasi kelima. Belum ada kabar mengenai komputer generasi kelima ini, banyak kabar yang beredar bahwa proyek komputer ini telah gagal, tetapi banyak juga yang mengatakan bahwa jika proyek komputer generasi kelima ini berhasil akan membawa perubahan yang signifikan terhadap paradigma komputerisasi di dunia.

Tujuan dilakukannya penelitian ini yaitu:

1) Untuk membuat suatu sistem yang dapat mendeteksi jenis kerusakan yang ada pada sebuah komputer

2) Memberikan solusi yang efektif dalam hal perbaikan perangkat komputer

3) Membantu user agar dapat mendeteksi dan memperbaiki komputer secara mandiri

Perkembangan teknologi komputer saat ini telah begitu pesat dari tahun ke tahun. Hampir semua kegiatan yang dilakukan tidak terlepas dari penggunaan sebuah komputer. Tetapi bagaimanapun komputer hanya sebuah mesin yang dapat mengalami malfungsi atau kerusakan dalam menjalankan fungsinya. Salah satu faktor yang mempengaruhi ketahanan komputer dapat berjalan dengan baik adalah bergantung kepada penggunanya itu sendiri.

Masalah kerusakan dari sebuah komputer seringkali merupakan kasus yang umum dan sering terjadi oleh kebanyakan pengguna lainnya. Masalah yang ditimbulkan oleh komputer kadangkala hanya memerlukan sebuah tingkat dasar pengetahuan tentang komputer. Tetapi terkadang masalah tersebut juga membutuhkan pengetahuan dan kemampuan tingkat tinggi mengenai komputer dan komponen yang ada dialamnya sehingga memerlukan seorang teknisi profesional untuk memperbaikinya [4].

\section{KAJIAN PENELITIAN}

Sistem Pakar merupakan salah satu bentuk lain dari Artificial Intelligence (AI) yang dimana penggunaannya berbasis dari pengetahuan dari beberapa/seorang pakar yang ahli dalam bidang tertentu. Sistem Pakar dikembangkan oleh komunitas AI di pertengahan 1960-an. Ide dasar di balik sistem pakar itu hanyalah keahlian, yang merupakan kumpulan luas dari pengetahuan khusus yang ditransfer dari manusia ke komputer. Sistem Pakar menyediakan sarana yang kuat dan fleksibel untuk mendapatkan sebuah solusi di dalam berbagai masalah yang sering terjadi dan yang tidak dapat ditangani oleh orang lain [5]. Fitur penting dari sebuah sistem pakar adalah bahwa mereka mampu menjelaskan kepada pengguna alur penalaran yang mengarah pada solusi masalah atau saran yang diinginkan. Ilmu pengetahuan dalam sistem pakar didasarkan pada teori ilmiah atau pada model fungsional atau kausal milik ahli tertentu.

Metode yang digunakan di dalam penelitian ini ada dua yaitu forward chaining dan case-based reasoning (CBR). Untuk metode forward chaining digunakan untuk menyelesaikan suatu permasalahan dengan awal menentukan fakta-fakta yang ada dan diakhiri dengan ditemukannya sebuah kesimpulan ataupun solusi dari permasalahan tersebut [6]. Misalnya ditemukan fakta-fakta berupa komponen seperti kipas dan power supply tidak dapat menyala dan komputer sering megalami restart, dari fakta-fakta tersebut kita dapat menyimpulkan bahwa penyebab utama masalah yang terjadi adalah komponen power supply pada cpu bermasalah. Metode case-based reasoning yaitu teknik pemecahan masalah dengan menggunakan kejadian yang terjadi dimasa lampau sebagai acuan untuk membentuk suatu solusi baru maupun hanya menggunakannya seperti yang lalu [7]. Metode ini memiliki 4 tahap siklus di dalam tahap pemecahan suatu masalah yaitu retrieve, reuse, revise, dan retain. Contohnya adalah ketika melakukan studi dokumen untuk mencari masalah yang kira-kira hampir sama dengan masalah yang sedang kita hadapi saat ini, setelah menemukannya kita dapat memilih apakah akan menggunakan solusi dari dokumen tersebut atau menggunakan solusi yang lebih efektif.

Sebuah sistem merupakan kumpulan dari beberapa objek dan penghubungnya secara bersamaan, antara objek dan atribut yang dihubungkan satu sama lain, dan dengan lingkungannya sehingga membentuk suatu kesatuan yang menyeluruh. Tetapi lain halnya menurut WHO (2009) pada [8] mengatakan bahwa definisi dari sistem yaitu suatu pendekatan untuk memecahkan masalah dengan sebuah masalah yang merupakan bagian dari masalah yang lebih luas dan bersifat dinamis. Dalam pengertian tersebut menunjukkan bahwa adanya beberapa bagian dan hubungan antara bagian lainnya, hal ini merujuk kepada kerumitan di dalam sistem yang meliputi kerjasama antar bagian interdependen [9].

Sistem pakar merupakan sebuah sistem komputer dengan cara kerja yaitu mengadopsi pengetahuan yang dimiliki oleh manusia dan memasukkannya ke dalam sistem [10]. Ilmu komputer mengembangkan sebuah perangkat lunak dan perangkat keras untuk meniru tindakan manusia. Simulasi aktivitas yang dilakukan manusia seperti penalaran, penglihatan, pembelajaran, pemecahan masalah, pemahaman bahasa alami dan sebagainya. Oleh karena itu sistem pakar dapat diartikan sebagai sistem komputer berbasis pengetahuan yang di dalamnya berisi beberapa pengetahuan yang dimiliki oleh para ahli. Basis Pengetahuan yang diambil dari teori-teori maupun pengalaman seorang pakar yang mahir pada bidangnya masing-masing [11]. Dalam pembentukannya, sistem pakar menggabungkan antara aturan penalaran inferensi dengan basis pengetahuan tertentu yang diberikan oleh seorang ahli dalam bidang yang mereka kuasai [12]. Sistem pakar juga memiliki beberapa komponen-komponen pembentuk di dalamnya seperti user interface, basis pengetahuan, akuisisi pengetahuan, 
inference machine, workplace, fasilitas penjelasan dan perbaikan pengetahuan [10].

Perkembangan teknologi komputer saat ini telah begitu pesat dari tahun ke tahun. Hampir semua kegiatan yang dilakukan tidak terlepas dari penggunaan sebuah komputer. Tetapi bagaimanapun komputer hanya sebuah mesin yang dapat mengalami malfungsi atau kerusakan di dalam menjalankan fungsinya. Salah satu faktor yang mempengaruhi ketahanan komputer dapat berjalan dengan baik adalah bergantung kepada penggunanya itu sendiri.

Masalah kerusakan dari sebuah komputer seringkali merupakan kasus yang umum dan sering terjadi oleh kebanyakan pengguna lainnya. Masalah yang ditimbulkan oleh komputer kadangkala hanya memerlukan sebuah tingkat dasar pengetahuan tentang komputer. Tetapi terkadang masalah tersebut juga membutuhkan pengetahuan dan kemampuan tingkat tinggi mengenai komputer dan komponen yang ada dialamnya sehingga memerlukan seorang teknisi profesional untuk memperbaikinya [13].

\section{Metode Penelitian}

\section{A. Mesin Inferensi Forward Chaining}

Pengertian menurut Arhami (2005) mengungkapkan bahwa forward chaining adalah suatu pendekatan yang digerakkan oleh tujuan (goal-driven). Forward Chaining mencari fakta yang sesuai dengan bagian dari IF dari aturan IF-THEN [14]. Cara kerja metode ini adalah dengan melakukan teknik pelacakan ke depan yang dimulai dengan informasi yang ada dan menggabungkan beberapa rule untuk menghasilkan suatu kesimpulan atau tujuan [15].

Strategi sistem ini dimulai dimulai dari inputan beberapa fakta, lalu menurunkan fakta-fakta dari beberapa aturan yang cocok pada basis pengetahuan (knowledge base) dan melanjutkan prosesnya hingga jawaban yang didapat sesuai. Forward chaining dapat dikatakan sebagai jenis penelusuran deduktif.

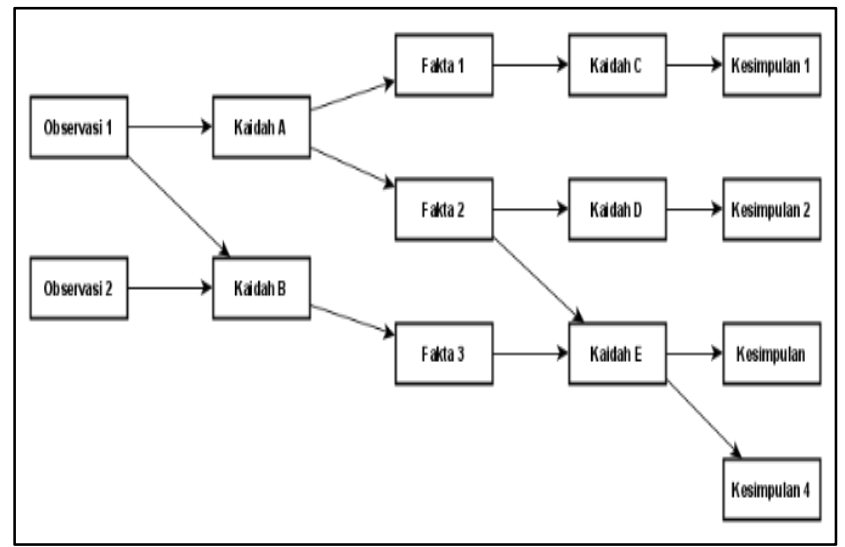

Gambar 1. Alur Forward Chaining [16]

\section{B. Metode Case-Base Reasoning}

Pada umumnya pengertian case-based reasoning (CBR) adalah suatu konsep penalaran dalam memecahkan suatu masalah melalui tulisan penanganan kasus-kasus yang pernah dilakukan oleh seorang pakar sebelumnya. CBR merupakan cara untuk menyelesaikan suatu kasus yang baru saja ditemukan dengan menggunakan cara adaptasi atau melihat solusi yang terdapat pada kasus-kasus yang terjadi sebelumnya dan yang mendekati dengan kasus terbaru tersebut [12]. Metode CBR ini menggunakan salah satu bentuk penyelesaian masalah dalam sistem pakar berbasis pengetahuan. Pada proses penyelesaian masalah, dimana dasar kasus adalah kumpulan kasus-kasus dengan solusi yang telah dicapai menggunakan kecerdasan buatan yang pusat penyelesaian masalahnya didasarkan kepada pengetahuan dari kasus-kasus sebelumnya.

\section{HASIL}

\section{A. Evaluasi Sistem Forward Chaining}

Di dalam memperbaiki suatu perangkat komputer tidak berbeda jauh dengan munculnya beberapa gangguan maupun kerusakan yang ada. Oleh karena itu penelitian ini dilakukan dengan tujuan untuk mencari dan memberikan solusi untuk jenis kerusakan komputer dengan metode forward chaining. Pada metode ini dijelaskan bahwa beberapa gejala kerusakan yang terlihat dapat diidentifikasi dari aspek jenis kerusakan dan solusi perbaikannya.

Tabel 1 merupakan tabel gejala yang berisi mengenai beberapa jenis gejala yang mungkin sering terjadi oleh kebanyakan dari komputer. Terdapat total 24 gejala yang didapatkan dari hasil pengumpulan data dengan menggunakan teknik wawancara, observasi dan juga studi dokumen.

Tabel 1.

Aturan Forward Chaining

\begin{tabular}{ll}
\hline \hline ID & \multicolumn{1}{c}{ Rule (IF THEN) } \\
\hline R1 & If G01 and G08 and G16 Then K01 \\
R2 & If G02 and G05 Then K02 \\
R3 & If G02 and G17 Then K03 \\
R4 & If G03 and G06 and G22 Then K04 \\
R5 & If G07 and G09 Then K05 \\
R6 & If G13 and G19 and G20 Then K06 \\
R7 & If G10 and G21 Then K07 \\
R8 & If G13 Then K08 \\
R9 & If G05 and G15 Then K09 \\
R10 & If G20 Then K10 \\
R11 & If G04 and G12 and G23 Then K11 \\
R12 & If G14 and G18 and G19 Then K12 \\
R13 & If G11 and G24 Then K13 \\
\hline \hline
\end{tabular}

Pada Tabel 1 dapat kita jabarkan beberapa aturan (rule) terkait dengan jenis kerusakan yang terjadi pada sebuah komputer seperti berikut:

- Rule 1: IF bunyi beep panjang terus menerus AND blue screen pada saat masuk ke dalam Windows THEN RAM bermasalah 
- $\quad$ Rule 2: IF tampilan awal BIOS tidak muncul AND sering terjadi hang/crash pada saat menjalankan aplikasi

THEN processor bermasalah

- $\quad$ Rule 3: IF tampilan awal bios tidak muncul

AND kinerja grafis terasa berat

THEN VGA card bermasalah

- Rule 4: IF muncul pesan error pada saat loading sistem operasi

AND sering melakukan scandisk pada saat booting

AND loading harddisk sangat lambat

THEN harddisk bermasalah

- Rule 5: IF driver audio tidak terdeteksi, meskipun driver sudah diinstall

AND muncul pesan error pada saat menjalankan aplikasi audio

THEN soundcard bermasalah

- $\quad$ Rule 6: IF suhu CPU cepat panas

AND semua perangkat input tidak terdeteksi

AND CPU menyala tetapi tidak menampilkan apapun THEN motherboard bermasalah

- $\quad$ Rule 7: IF komputer sering mati secara tiba-tiba pada saat dinyalakan

AND lampu indikator CPU tidak menyala

THEN power supply bermasalah

- $\quad$ Rule 8: IF suhu CPU cepat panas

THEN fan bermasalah

- Rule 9: IF sering terjadi hang/crash pada saat menjalankan aplikasi

AND komputer lambat pada saat menjalankan aplikasi THEN kapasitas RAM kurang

- Rule 10: IF CPU menyala tetapi tidak menampilkan apapun

THEN VGA card rusak

- $\quad$ Rule 11: Harddisk mengeluarkan suara aneh

AND harddisk tidak terdeteksi

AND file corrupt tanpa sebab

THEN harddisk rusak

- $\quad$ Rule 12: IF USB tidak dapat terdeteksi

AND CPU mati total

AND semua perangkat input tidak terdeteksi

THEN motherboard rusak

- $\quad$ Rule 13: IF kipas pada power supply tidak berputar AND tidak ada aliran listrik yang mengalir pada CPU THEN power supply rusak

\section{B. Evaluasi Sistem Case-Based Reasoning}

Pada proses evaluasi ini dapat dilakukan setelah mendapatkan seluruh data yang dibutuhkan. Metode ini bertujuan untuk mencari tingkat kemiripan antara kasus baru dengan kasus lama tentang kerusakan pada komputer dengan cara melakukan perhitungan yang menggunakan proses pembobotan rumus K-Nearest Neighbor. Cara untuk melakukan perhitungan nilai kemiripan terhadap kasus lama dengan kasus baru adalah dengan menggunakan algoritma K-Nearest Neighbor.

Tabel 2.

Kasus Baru

\begin{tabular}{|c|c|}
\hline \multirow{2}{*}{ Kode } & Kasus Baru \\
\hline & Gejala Pada Komputer \\
\hline G20 & $\begin{array}{l}\text { Semua Perangkat Keras Menyala Tetapi Tampilan Tidak } \\
\text { Muncul Di Monitor }\end{array}$ \\
\hline G19 & Semua Perangkat Inputan Tidak Bekerja \\
\hline G18 & CPU Tidak Dapat Dinyalakan \\
\hline G05 & Komputer Sering Tidak Merespon (Not Responding) \\
\hline G01 & Terdengar Bunyi Beep Terus Menerus \\
\hline G10 & CPU Sering Mati Dengan Sendirinya \\
\hline
\end{tabular}

Perhitungan Kasus VI:

Tabel 3.

Menentukan Nilai Kemiripan Kasus Baru dengan Lama

\begin{tabular}{|c|c|c|c|}
\hline \multirow{3}{*}{ Kode } & Kasus Lama KL006 & \multirow{3}{*}{ Bobot } & \multirow{3}{*}{$\begin{array}{r}\text { Gejala } \\
\text { Baru }\end{array}$} \\
\hline & Motherboard Bermasalah & & \\
\hline & Gejala Pada Komputer & & \\
\hline G14 & USB Tidak Dapat Terdeteksi & 0.75 & 1 \\
\hline G18 & CPU Mati Total & 1 & 1 \\
\hline G13 & Suhu CPU Cepat Panas & 0.5 & 0 \\
\hline G19 & $\begin{array}{l}\text { Semua Perangkat Input Tidak } \\
\text { Terdeteksi }\end{array}$ & 1 & 1 \\
\hline G20 & $\begin{array}{l}\text { CPU Menyala Tetapi Tidak } \\
\text { Menampilkan Apapun }\end{array}$ & 0.75 & 1 \\
\hline
\end{tabular}

Nilai Kemiripan Kasus VI:

Similiarity $(\mathrm{S}, 06)=\frac{\left[\left(1^{*} 0.75\right)+\left(1^{*} 1\right)+\left(0^{*} 0.5\right)+\left(1^{*} 1\right)+\left(1^{*} 0.75\right)\right]}{0.75+1+0.5+1+0.75}$

$=0.875 \times 100 \%$

$=87.5 \%$

Pada rumus diatas dapat dikatakan bahwa tingkat kemiripan antara kasus lama dengan kasus baru mendekati kata mirip, dengan hasil yang didapat sebesar $87.5 \%$. Kasus IV belum dapat disimpulkan menjadi hasil kemiripan tertinggi sampai semua perhitungan kasus selesai dihitung.

Dan dengan demikian kasus baru yang memiliki tingkat nilai kemiripan dengan kasus lama ada pada kasus lama dengan kode KL006 dengan perolehan presentase nilai sebesar 87.5\% dan kesimpulan yang didapat berupa kerusakan yang terjadi ialah jenis kerusakan pada motherboard. Solusi yang dapat diberikan sebagai berikut:

1) Ganti dengan motherboard baru.

2) Lepaskan semua komponen yang ada pada motherboard kecuali kabel power supply, keluarkan motherboard dari casing, lalu cobalah nyalakan motherboard dan tes menggunakan tespen apakah arus listriknya berjalan 


\section{KESIMPULAN}

Dari serangkaian penelitian yang telah dilakukan sebelumnya mulai dari proses analisa hingga proses evaluasi di dalam mendeteksi kerusakan komputer denga menggunakan metode Case Based Reasoning dan Forward Chaining maka dapat disimpulkan bahwa ketika mengidentifikasi beberapa gejala dan jenis kerusakan pada suatu perangkat komputer dapat dilihat dari beberapa gejala yang sebelumnya pernah terjadi serta melakukan perhitungan yang valid guna membantu agar tingkat kepastian dari jenis kerusakan tersebut menjadi lebih tinggi. Penerapan metode Forward Chaining dalam mencari jenis kerusakan komputer dilakukan dengan menggunakan banyak cara antara lain mulai dari menggunakan tabel berbasis aturan hingga sampai kepada pembuatan pohon keputusan. Di dalam penerapan metode Case Based Reasoning, dapat dikatakan bahwa metode ini menggunakan cara perbandingan dimana membandingkan kasus lama dengan kasus baru yang dimana kedua kasus tersebut memiliki bobot nilai tersendiri

\section{REFERENSI}

[1] D. Mandell et al., "Intracranial vessel wall MRI: principles and expert consensus recommendations of the American Society of Neuroradiology," vol. 38, no. 2, pp. 218-229, 2017.

[2] S. Suminten and R. Rani, "Sistem Pakar Diagnosa Kerusakan Laptop Menggunakan Metode Forward Chaining," vol. 2, no. 3, pp. 604-610, 2018.

[3] W. U. Setiabudi, E. Sugiharti, and F. Y. Arini, "Expert system diagnosis dental disease using Certainty Factor method," vol. 4, no. 1, pp. 43-50, 2017.
[4] A. Sunarya, S. Santoso, and W. Sentanu, "Sistem pakar untuk mendiagnosa gangguan jaringan lan," vol. 8, no. 2, pp. 1-11, 2015.

[5] H. K. Jabbar and R. Z. Khan, "Survey on Development of Expert System from 2010 to 2015," in Proceedings of the Second International Conference on Information and Communication Technology for Competitive Strategies, 2016, pp. 1-7.

[6] A. Farizi, "Sistem Pakar Untuk Mendiagnosa Kerusakan Komputer Dengan Menggunakan Metode Forward Chaining," Edu Komputika Journal, vol. 1, no. 2, 2014.

[7] D. A. Sharaf-El-Deen, I. F. Moawad, and M. Khalifa, "A new hybrid case-based reasoning approach for medical diagnosis systems," vol. 38, no. 2, pp. 1-11, 2014.

[8] A. Heryana and M. KM, "Kepemimpinan Berfikir Sistem."

[9] M. Marimin, "Teori dan aplikasi sistem pakar dalam teknologi manajerial," no. January, vol. 2007, 2009.

[10] Y. Wijayana, "Sistem Pakar Kerusakan Hardware Komputer dengan Metode Backward Chaining," Universitas Muhammadiyah Semarang, 2018.

[11] M. A. Raharja, "Perancangan dan Implementasi Aplikasi Sistem Pakar Untuk Kerusakan Speaker Aktif dengan Metode Backward Chaining," Jurnal Teknologi Informasi dan Komputer, vol. 2, no. 1, 2017.

[12] S. Kosasi, "Pembuatan Aplikasi Diagnosa Kerusakan Mesin Sepeda Motor Matic dengan Case-Based Reasoning," vol. 2, no. 3, pp. 192-206, 2015.

[13] H. Chrystianto, "Rancang Bangun Sistem Pakar Troubleshooting Kerusakan Hardware Laptop Berbasis Android," Perpustakaan Universitas Teknokrat Indonesia, 2017.

[14] A. A. Rismayadi, "Perancangan Aplikasi Sistem Pakar Diagnosa Kerusakan Hardware Komputer Metode Forward Chaining," Jurnal Informatika, vol. 3, no. 2, 2016.

[15] J. Lestari, "Analisis Sistem Deteksi Kerusakan Komputer Dengan Menggunakan Metode Forward Chaining," Inspiration: Jurnal Teknologi Informasi dan Komunikasi, vol. 6, no. 1, 2016.

[16] Z. H. Gultom, "Sistem Pakar Untuk Mendeteksi Kerusakan Pada Sepeda Motor Dengan Menggunakan Metode Forward Chaining Berbasis Web," vol. 9, no. 1, pp. 42-58, 2018. 